\title{
Inhibition of proliferation, migration and invasiveness of endothelial murine cells culture induced by resveratrol
}

\author{
DARIUSZ ROKICKI ${ }^{1}$, ROBERT ZDANOWSKI ${ }^{2}$, SEAWOMIR LEWICKI ${ }^{2}$, MONIKA LEŚNIAK ${ }^{2}$ \\ MILENA SUSKA ${ }^{2}$ ELŻBIETA WOJDAT ${ }^{3}$, EWA SKOPIŃSKA-RÓŻEWSKA ${ }^{4,5}$, PIOTR SKOPIŃSKI ${ }^{6,7}$ \\ ${ }^{1}$ Thea Poland, Warsaw, Poland \\ ${ }^{2}$ Department of Regenerative Medicine, Military Institute of Hygiene and Epidemiology, Warsaw, Poland \\ ${ }^{3}$ Ludwik Hirszfeld Institute of Immunology and Experimental Therapy, Polish Academy of Sciences, Wroclaw, Poland \\ ${ }^{4}$ Pathology Department, Center for Biostructure Research, Medical University of Warsaw, Warsaw, Poland \\ ${ }^{5}$ Military Institute of Hygiene and Epidemiology, Warsaw, Poland \\ ${ }^{6}$ Department of Histology and Embryology, Center for Biostructure Research, Medical University of Warsaw, Warsaw, Poland \\ ${ }^{7}$ Second Department of Ophthalmology, Warsaw Medical University, Warsaw, Poland
}

\begin{abstract}
Angiogenesis is a multi-stage process of new vessel development which involves migration, proliferation and differentiation of endothelial cells. Pathological angiogenesis plays a crucial role in the pathomechanism of various ischemic, malignant and inflammatory disorders. Among eye diseases, macular degeneration (AMD) and proliferative diabetic retinopathy are a major public health issue as the most common causes of blindness. Since angiogenesis plays a crucial role in these conditions, there has been an increased interest in evaluating anti-angiogenic agents in their treatment. The polyphenol resveratrol found in the skin of red grapes, red wine, peanuts and other natural sources, controls proliferation of the cells, induces differentiation and induces apoptosis in various malignant cell lines. Modulation of angiogenesis by this compound has been considered as a very exciting topic and subject of further investigations.

The aim of our study was in vitro assessment of resveratrol's influence on proliferation, migration and invasion of an immortalized murine endothelial cell line from peripheral lymph node HEC clone a10. Resveratrol was shown to inhibit the proliferation of the endothelial cells in MTT (at 1, 10 and $50 \mu M)$ and AlamarBlue (at $50 \mu M)$ assays, and at a concentration of $50 \mu M$ significantly inhibited migration of endothelial cells. A concentration-dependent decrease in invasion potential of endothelial cells incubated with resveratrol $10 \mu M$ and $50 \mu M$ was detected.

These promising in vitro results might encourage investigators to test efficacy and safety of resveratrol more extensively in the clinical practice, as a natural and safe anti-angiogenic agent.
\end{abstract}

Key words: resveratrol, murine endothelial cells, proliferation, migration, invasion.

(Centr Eur J Immunol 2014; 39 (4): 449-454)

\section{Introduction}

Angiogenesis is a multi-stage process of new vessel development which involves migration, proliferation and differentiation of endothelial cells. These actions lead to the formation of solid endothelial cell sprouts, followed by the development of vascular loops and finally capillary tubes with interendothelial tight junctions [1]. Migration and proliferation also underlie a non-sprouting (intussusceptive) microvascular growth [2]. The entire process of angiogenesis is highly regulated by diverse pro-angiogenic and anti-angiogenic proteins and growth factors. In contrast to embryogenesis, postnatal angiogenesis is associated with abnormalities in a vascular structure and/or functions [3]. The unbalanced pro-angiogenic course is an essential key element in the pathomechanism of a vicious cycle development in various ischemic, malignant and inflammatory disorders [4]. Since angiogenesis plays a crucial role in these conditions, there has been an increased interest in evaluating anti-angiogenic agents in their treatment [5]. Numerous data revealed a beneficial effect of such approach [6-8]. Recently available monoclonal humanized anti-VEGF antibodies such as ranibizumab and bevacizumab or aflibercept (VEGF-Trap), a fusion protein

Correspondence: Dariusz Rokicki, Thea Poland, Cicha 7, 00-353 Warsaw, Poland, tel. +48 22 642 87 77, e-mail: rokdar@yahoo.com 
with high VEGF affinity, have brought effects especially in tumor development and in ocular neovascularization [9].

Public health data indicate that the global burden of malignancies in the population, measured by incidence, mortality, as well as social and economic costs, is substantial. Based only on US data, the number of new cases of all cancer sites was 463.0 per 100,000 men and women per year [10].

Taking into account eye diseases, well recognized age-related macular degeneration (AMD) is a major public health issue. It is considered as the most common cause of legal blindness in the developed world and it will become more prevalent with an expected increase in the population aged over 65 years of age. Overall, the 3 -year incidence of exudative AMD in the US is estimated to be between 9.4 and 11.4 per 1000 Americans aged 65 and older (based only on those diagnosed and treated by ophthalmologists for the condition) [11].

An estimated 700,000 Americans have proliferative diabetic retinopathy, actually an advanced stage of this disease, with an annual incidence of 65,000. Approximately 500,000 persons have clinically significant macular edema, with an annual incidence of 75,000 [12].

Indeed there is a growing demand to develop new therapeutic compounds to treat various diseases or at least to modify their typical course.

The polyphenolic phytoalexin, resveratrol (3,5,4'-trihydroxystilbene) (RSV), found in the skin of red grapes, red wine, peanuts or Polygonum cuspidate roots, known for its pleiotropic mode of action [13, 14], has received wide attention due to its possible role in the prevention of human pathologic processes, including cancer, diabetic retinopathy, or cardiovascular diseases $[14,15]$.

Results of numerous basic researches suggest that resveratrol controls cells' proliferation, induces differentiation and apoptosis in various malignances [15]. In turn, the impact of resveratrol on vascularization in certain conditions seems to be vague [16]. Pro-angiogenic effects of this agent were observed in the infarcted myocardium [17, 18], whereas anti-angiogenic effects have been noted in other tissues [14]. The modulation of the angiogenesis by this compound has been considered as a very exciting topic and subject of further investigations.

The aim of our study was to assess resveratrol's influence on the proliferation, migration and invasion of an immortalized murine endothelial cell line from peripheral lymph node HEC clone a10 [19, 20].

\section{Material and methods}

\section{Cell culture}

HECa10 mouse endothelial cell line was kindly provided by professor Claudine Kieda from the Centre of Molecular Biophysics, Orléans, France. The murine HECa10 cell line obtained from endothelial cells of the mouse peripheral lymph nodes immortalized by transfection of plasmid with the gene for the large $\mathrm{T}$ antigen of Simian virus 40 was used in the experiments $[19,20]$. Typical endothelial features of HECa10 mouse endothelial cell line, such as the presence of angiotensin-converting enzyme, von Willebrand factor, VE-cadherin, and the intracellular E-selectin, are preserved [20].

Cells were maintained in $75 \mathrm{~cm}^{2}$ (Becton Dickinson Falcon) culture flasks under standard culture conditions $\left(5 \% \mathrm{CO}_{2}, 37^{\circ} \mathrm{C}, 95 \%\right.$ R.H.) with medium renewal every 2-3 days.

\section{Proliferation assays}

Proliferation of endothelial cells was estimated using MTT [3-(4,5-dimethylthiazol-2-yl)-2,5-diphenyl tetrazolium bromide], and AlamarBlue ${ }^{\circledR}$ (resazurin), a dye that measures the metabolic activity of living cells.

\section{MTT assay}

The cells (in log phase growth stage) were harvested (Accutase, PAA), centrifuged (400 g, 5 min.), suspended in culture medium (DMEM, $4.5 \mathrm{~g} / \mathrm{ml}$ glucose with L-glutamine, $10 \%$ FBS, $50 \mathrm{U} / \mathrm{ml}$ penicillin, $50 \mu \mathrm{g} / \mathrm{ml}$ streptomycin, Gibco) to the final density of $0.5 \times 10^{5}$ cells $/ \mathrm{ml}$ and seeded into a $96-$-well plate $(100 \mu \mathrm{l}$ per well). Twenty-four hours after seeding, cells were washed twice with PBS, and resveratrol $(1,5,10,50$ or $100 \mu \mathrm{M}$, Sigma Aldrich) dissolved in culture medium was added.

Twenty-four hours later the culture medium was discarded and fresh culture medium with MTT $(0.5 \mathrm{mg} / \mathrm{ml})$ was added directly to the wells. After 4-hour incubation $\left(37^{\circ} \mathrm{C}\right.$ and $5 \% \mathrm{CO}_{2}$ ) the medium was discarded and $100 \mu \mathrm{l}$ of DMSO was added to all the wells to dissolve the formazan crystals. The absorbance was measured at $570 \mathrm{~nm}$ by FLUOstar Omega reader (BMG Labtech).

\section{AlamarBlue}

AlamarBlue assay was performed as described previously [21]. The cells (in log phase growth stage) were harvested, centrifuged, suspended in culture medium (DMEM, $4.5 \mathrm{~g} / \mathrm{ml}$ glucose with L-glutamine, 10\% FBS, $50 \mathrm{U} / \mathrm{ml}$ penicillin, $50 \mu \mathrm{g} / \mathrm{ml}$ streptomycin), to the final density of $0.5 \times 10^{5}$ cells $/ \mathrm{ml}$ and seeded into a 96-well plate $(100 \mu \mathrm{l}$ per well). Twenty-four hours after seeding, cells were washed twice with PBS, and resveratrol (1, 5, $10,50$ or $100 \mu \mathrm{M})$ dissolved in culture medium was added.

Twenty-four hours later the culture medium was discarded and fresh culture medium with AlamarBlue (1:10 PAA) was added directly to the wells. Fluorescence (excitation $544 \mathrm{~nm}$ and emission $590 \mathrm{~nm}$ ) was measured directly in the wells after $24 \mathrm{~h}$ incubation using FLUOstar Omega reader. 


\section{Migration assay}

The cells (in log phase growth stage) were harvested, centrifuged, suspended in medium (DMEM, $4.5 \mathrm{~g} / \mathrm{ml}$ glucose with L-glutamine, $10 \% \mathrm{FBS}, 50 \mathrm{U} / \mathrm{ml}$ penicillin, $50 \mu \mathrm{g} / \mathrm{ml}$ streptomycin) with the addition of $10 \mu \mathrm{g} / \mathrm{ml} \mathrm{DilC}_{12}$ (3) fluorescent dye (Becton Dickinson) and stained for 1 hour in standard conditions. Next, cells were harvested, centrifuged and suspended in FBS-free culture medium to the final density of $8 \times 10^{5} \mathrm{cell} / \mathrm{ml}$. $250 \mu \mathrm{l}$ of the prepared cells suspension $\left(2 \times 10^{5}\right.$ cell) was added on the $3 \mu \mathrm{m}$ FluoroBlok inserts (Becton Dickinson) and placed in a 24 -well plate. Chambers under the inserts were filled with $750 \mu$ of culture medium (DMEM, $4.5 \mathrm{~g} / \mathrm{ml}$ glucose with L-glutamine, 5\% FBS, $50 \mathrm{U} /$ $\mathrm{ml}$ penicillin, $50 \mu \mathrm{g} / \mathrm{ml}$ streptomycin). 10 or $50 \mu \mathrm{M}$ of resveratrol were added to the lower chamber. As a control, culture medium without resveratrol was used. As a negative control, FBS-free culture medium was used. The fluorescence (excitation $549 \mathrm{~nm}$ and emission $565 \mathrm{~nm}$ ) was measured after $24 \mathrm{~h}$ exposure directly in the inserts using the FLUOstar Omega reader with "bottom optic" option. The results were shown as the relative fluorescence units - RFU (mean \pm SEM).

\section{Invasion assay}

The cells (in log phase growth stage) were harvested, centrifuged, suspended in FBS-free culture medium to the final density of $8 \times 10^{5} \mathrm{cell} / \mathrm{ml}$. $250 \mu \mathrm{l}$ of the prepared cells suspension $\left(2 \times 10^{5}\right.$ cell $)$ was added on the $3 \mu \mathrm{m}$ Fluoro Blok inserts covered with Matrigel TM (Becton Dickinson) and placed in a 24-well plate. Chambers under the inserts were filled with $750 \mu \mathrm{l}$ of culture medium (DMEM, $4.5 \mathrm{~g} / \mathrm{ml}$ glucose with L-glutamine, $5 \% \mathrm{FBS}, 50 \mathrm{U} / \mathrm{ml}$ penicillin, $50 \mu \mathrm{g} / \mathrm{ml}$ streptomycin). 10 or $50 \mu \mathrm{M}$ of resveratrol were added to the lower chamber. As a control, culture medium without resveratrol was used. As a negative control, FBS-free culture medium was used. After $24 \mathrm{~h}$ incubation the medium was discarded and $4 \mu \mathrm{M}$ of fluorescent dye Calcein AM (Becton Dickinson) in PBS was added. One hour later both plate and inserts were washed twice with PBS and fluorescence (excitation $485 \mathrm{~nm}$ and emission $510 \mathrm{~nm}$ ) was measured directly in the inserts using the FLUOstar Omega reader with "bottom optic" option. The results were shown as the relative fluorescence units - RFU (mean \pm SEM).

\section{Statistical analysis}

Statistical analysis of the results was performed with two-way (proliferation) and one-way (migration and invasiveness) ANOVA with Tukey's Multiple Comparison Test (GraphPadPrism).

\section{Results and discussion}

Proliferation and migration of endothelial cells are crucial for new blood vessel formation during angiogenesis

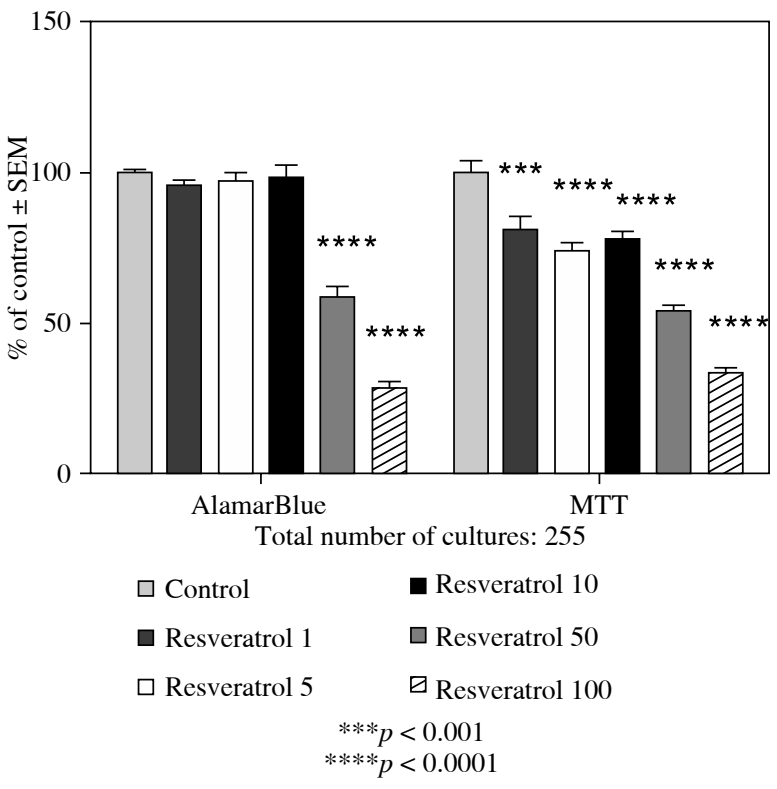

MTT assay was performed on a 96-well plate on cells in log phase growth stage. The cells were exposed to resveratrol for 24 hours. The absorbance was measured at $570 \mathrm{~nm}$ by FLUOstar Omega reader. The results are shown as a percentage of values obtained from control condition (mean \pm SEM).

AlamarBlue assay - The cells (in log phase growth stage) were harvested, centrifuged, suspended in the culture medium (DMEM, $4.5 \mathrm{~g} / \mathrm{ml}$ glucose with L-glutamine, $10 \% \mathrm{FBS}, 50 \mathrm{U} / \mathrm{ml}$ penicillin, $50 \mu \mathrm{g} / \mathrm{ml}$ streptomycin), to the final density of $0.5 \times 10^{5}$ cells $/ \mathrm{ml}$ and seeded into a 96 -well plate $(100 \mu \mathrm{l}$ per well). Twenty-four hours after seeding, cells were washed twice with PBS, and resveratrol $(1,5,10$, 50 or $100 \mu \mathrm{M}$ ) dissolved in the culture medium was added.

Twenty-four hours later, the culture medium was discarded and fresh culture medium with AlamarBlue (1:10, PAA) was added directly to the wells. Fluorescence (excitation $544 \mathrm{~nm}$ and emission $590 \mathrm{~nm}$ ) was measured directly in the wells after $24 \mathrm{~h}$ incubation using FLUOstar Omega reader.

Fig. 1. The effect of resveratrol concentration $(1,5,10,50$ and $100 \mu \mathrm{M})$ on the proliferation rate of HECa10 mouse endothelial cell line measured by MTT or AlamarBlue assays

[22]. Most steps in this cascade and the influence of potential anti-angiogenic agents on behavior of endothelial cells can be analyzed in vitro including their proliferation, migration and invasion potential.

The impact of resveratrol on the angiogenic activity of endothelial cells line HECa10 was assessed in our research.

Resveratrol was shown to inhibit, in a concentration-dependent manner, the proliferation of endothelial cells measured by MTT-assay. The results are shown in Figure 1 as a percentage of mean control values (mean \pm SEM).

The maximal concentration of resveratrol of $100 \mu \mathrm{M}$ was cytotoxic for this cell line and therefore it was not considered during further examinations. 


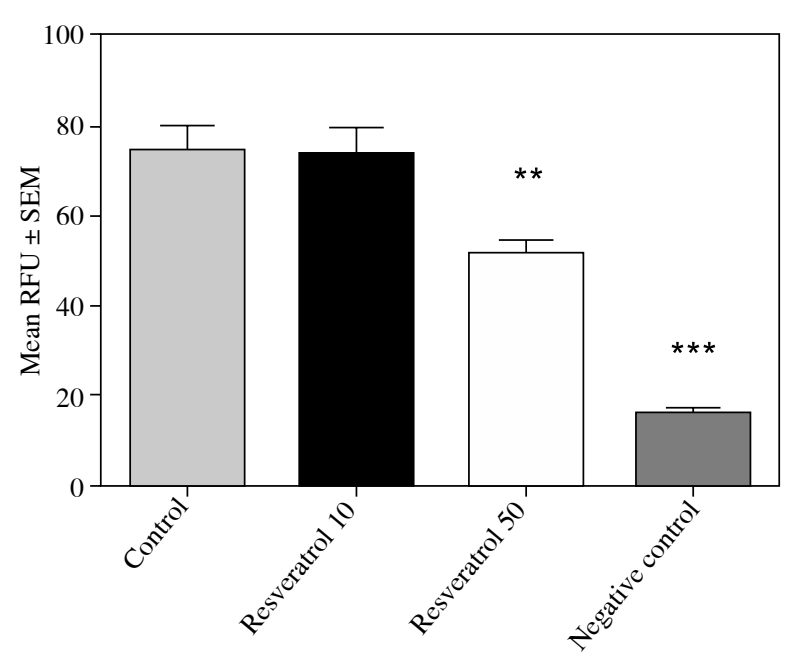

Total number of cultures: 53

$$
\begin{aligned}
* * & <0.01 \\
* * * & <0.001
\end{aligned}
$$

Migration was performed on a 24-well plate with $3 \mu \mathrm{m}$ FluoroBlok inserts. Cells were placed on inserts and resveratrol $(10$ or $50 \mu \mathrm{M})$ was added to a lower chamber of the plate. Fluorescence of migrating cells was measured after 24 hour incubation with resveratrol. The results are shown as the relative fluorescence units (RFU) (mean \pm SEM).

Fig. 2. The effect of resveratrol concentration (10 and 50 $\mu \mathrm{M})$ on HECa10 migration measured by the fluorescence method (staining with $10 \mu \mathrm{g} / \mathrm{ml} \mathrm{DilC}_{12}$ (3) fluorescent dye)

These results were confirmed in AlamarBlue colorimetric method as seen in Figure 1. Our results obtained from these two proliferation assays (MTT/resazurin) proved to be consistent. According to our knowledge, this is one of the first reports utilizing both methods in assessing resveratrol effect in MTT/resazurin proliferations' assays [23].

Except for RSV higher concentrations, which performed consistently in both assays, the AlamarBlue assay was less sensitive than the MTT assay for lower concentrations of $\operatorname{RSV}(1,5,10 \mu \mathrm{M})$. One has to be conscious when interpreting data that variation between replicates should be considered.

The results of the migration assay are shown in Figure 2 as the relative fluorescence units (RFU) of treated and control cells (mean \pm SEM). As presented, resveratrol only at higher concentration of $50 \mu \mathrm{M}$ significantly inhibited migration of endothelial cells.

Figure 3 presents the results of the invasion assay, shown as the RFU of treated and control cells (mean \pm SEM). A concentration-dependent decrease in invasion potential of endothelial cells incubated with resveratrol $10 \mu \mathrm{M}$ and $50 \mu \mathrm{M}$ was detected. It should be underlined

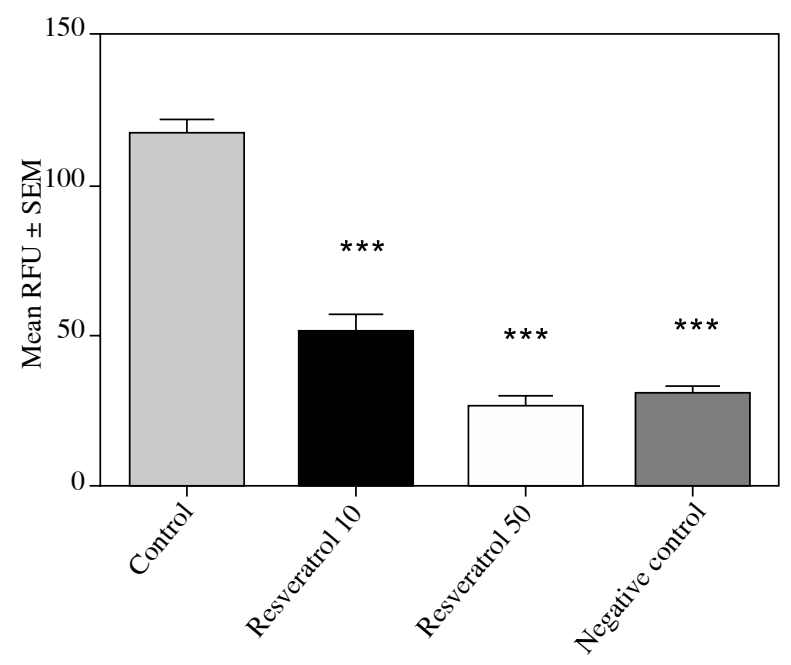

Total number of cultures: 40

$$
* * * p<0.001
$$

Invasion potential was performed on a 24 -well plate with $3 \mu \mathrm{m}$ FluoroBlok inserts covered with matrigel. Cells were placed on inserts and resveratrol $(10$ or $50 \mu \mathrm{M})$ was added to a lower chamber of the plate. Fluorescence of migrating cells was measured after 24 hour incubation with resveratrol. The results are shown as the relative fluorescence units $(\mathrm{RFU})$ (mean $\pm \mathrm{SEM})$.

Fig. 3. The effect of resveratrol concentration (10 and $50 \mu \mathrm{M}$ ) on HECa10 invasion potential measured by the fluorescence method (staining $4 \mu \mathrm{M}$ Calcein AM fluorescent dye)

that a higher concentration of resveratrol practically completely inhibited endothelial cells' migration at the level of the negative control.

This preliminary study focused on the impact of resveratrol on the proliferation, migration and invasion potential of endothelial cells under normal conditions. However, that will be a good starting point for our further research to evaluate a response to resveratrol in a stimulated endothelial cell line in hypoxia conditions.

Furthermore, in every biological model the role of cytokines, signaling molecules, cannot be overestimated. Vascular endothelial growth factor (VEGF), basic fibroblast growth factor (bFGF) and interleukin (IL)-8 are thought to be linked to the significant stimulation of angiogenesis $[24,25]$. The influence of resveratrol on cytokines and cell adhesion molecules as vascular cell adhesion molecule 1 (VCAM-1), intercellular adhesion molecule 1 (ICAM-1) would be very helpful to understand underlying mechanisms in angiogenesis' modulation exerted by these molecules. In human lung adenocarcinoma cells, the inhibitory effect of resveratrol on cells invasion is mediated through inactivation of stress-activated protein kinase/c- 
JUN, N-terminal kinase (SAPK/JNK) phosphorylation and decreasing matrix metalloproteinase-2 expression [26].

Certainly it would allow for its wider use in clinical trials assessing the efficacy and safety in clinical practice. Nowadays, there are numerous data indicating potential efficacy of resveratrol in inhibition of cell growth and induction of apoptosis in several cancer cell lines [27-32].

Resveratrol seems to be a promising agent in combination with radiation therapy probably due to the increase in cancer cells' radiation sensitivity (including e.g. melanoma, non-small cell lung cancer, prostate cancer or Merkel cell carcinoma) by inhibiting proliferation and promoting apoptosis or via enhancing ionizing radiation-induced premature senescence [33-36].

Resveratrol received recently an increasing attention due to its possible role in the prevention of exudative age-related macular degeneration or diabetic retinopathy. Recent data demonstrate that resveratrol suppressed hypoxia-induced choroidal vascular endothelial cell (CVEC) proliferation characteristic of exudative age-related macular degeneration. The mechanism seems to be mediated through activation of the SAPK/JNK pathway [37].

Potential inhibitory effect of three polyphenolic agents such as epigallocatechin gallate (EGCG), resveratrol and curcumin on the proliferation of human retinal pigment epithelial (RPE) cells was investigated by Alex et al. The three molecules inhibited the increase in RPE cell numbers at all time points, with resveratrol being the most efficient and curcumin being the least efficient [38].

\section{Conclusions}

These promising in vitro results with resveratrol might encourage investigators to test efficacy and safety of this agent more extensively in the clinical practice, in the prevention of exudative age-related macular degeneration or diabetic retinopathy.

\section{The authors declare no conflict of interest.}

\section{References}

1. Carmeliet P (2000): Mechanisms of angiogenesis and arteriogenesis. Nat Med 6: 389-395.

2. Ribatti D, Crivellato E (2012): Sprouting angiogenesis, a reappraisal. Dev Biol 372: 157-165.

3. Kalka C, Asahara T, Krone W, Isner JM (2000): Angiogenesis and vasculogenesis. Therapeutic strategies for stimulation of postnatal neovascularization. Herz 25: 611-622.

4. Carmeliet P (2005): Angiogenesis in life, disease and medicine. Nature 438: 932-936.

5. Folkman J (1971): Tumor angiogenesis: therapeutic implications. N Engl J Med 285: 1182-1186.

6. Aprile G, Fontanella C, Lutrino ES, et al (2013): Angiogenic inhibitors for older patients with advanced colorectal cancer: does the age hold the stage? World J Gastroenterol 19: 21312140.

7. Saif MW (2013): Is there a benefit from addiction to anti-VEGF therapy in patients with colorectal cancer? Anticancer Res 33: 2377-2380.

8. Skopinska-Rozewska E, Malinowski M, Wasiutynski A, et al (2008): The influence of Rhodiola quadrifida 50\% hydro-alcoholic extract and salidroside on tumor-induced angiogenesis in mice. Pol J Vet Sci 11: 97-100.

9. Vedula SS, Krzystolik MG (2008): Antiangiogenic therapy with anti-vascular endothelial growth factor modalities for neovascular age-related macular degeneration. Cochrane Database Syst Rev 2: CD005139.

10. Howlader N, Noone AM, Krapcho M, et al (2013): SEER Cancer Statistics Review, 1975-2010, National Cancer Institute. Bethesda, MD. http://seer.cancer.gov/csr/1975_2010.

11. Javitt JC, Zhou Z, Maguire MG, et al (2003): Incidence of exudative Age-related Macular Degeneration among elderly Americans. Ophthalmology 110: 1534-1539.

12. Patz A, Smith RE (1991): The ETDRS and diabetes 2000. Ophthalmology 98: 730-740.

13. Borriello A, Cucciolla V, Della Ragione F, Galletti P (2010): Dietary polyphenols: focus on resveratrol, a promising agent in the prevention of cardiovascular diseases and control of glucose homeostasis. Nutr Metab Cardiovasc Dis 20: 618625

14. Harikumar KB, Aggarwal BB (2008): Resveratrol: a multitargeted agent for age-associated chronic diseases. Cell Cycle 7: 1020-1035.

15. Pace-Asciak CR, Hahn S, Diamandis EP, et al. (1995): The red wine phenolics trans-resveratrol and quercetin block human platelet aggregation and eicosanoid synthesis: implications for protection against coronary heart disease. Clin Chim Acta 235: 207-219.

16. Chen Y, Tseng SH (2007): Review. Pro- and anti-angiogenesis effects of resveratrol. In Vivo 21: 365-370.

17. Penumathsa SV, Koneru S, Samuel SM, et al. (2008): Strategic targets to induce neovascularization by resveratrol in hypercholesterolemic rat myocardium: role of caveolin-1, endothelial nitric oxide synthase, hemeoxygenase-1, and vascular endothelial growth factor. Free Radic Biol Med 45: 1027-1034.

18. Fukuda S, Kaga S, Zhan L, et al. (2006): Resveratrol ameliorates myocardial damage by inducing vascular endothelial growth factor-angiogenesis and tyrosine kinase receptor Flk-1. Cell Biochem Biophys 44: 43-49.

19. Bizouarne N, Denis V, Legrand A, et al. (1993): A SV-40 immortalized murine endothelial cell line from peripheral lymph node high endothelium expresses a new alpha-L-fucose binding protein. Biol Cell 79: 209-218.

20. Kieda C, Paprocka M, Krawczenko A, et al. (2002): New human microvascular endothelial cell lines with specific adhesion molecule phenotypes. Endothelium 9: 247-261.

21. Zdanowski R, Stankiewicz W, Kaminski A, et al. (2012): The effect of sterilization by irradiation of human pericardium and skin frozen tissues on their ability to influence the proliferation of endothelial cells in vitro. Centr Eur J Immunol 37: 119-122.

22. Lamalice L, Le Boeuf F, Huot J (2007): Endothelial cell migration during angiogenesis. Circ Res 100: 782-794.

23. Menard C, Bastianetto S, Quirion R (2013): Neuroprotective effects of resveratrol and epigallocatechin gallate polyphenols 
are mediated by the activation of protein kinase $\mathrm{C}$ gamma. Front Cell Neurosci 7: 281.

24. Padró T, Bieker R, Ruiz S, et al. (2002): Overexpression of vascular endothelial growth factor (VEGF) and its cellular receptor KDR (VEGFR-2) in the bone marrow of patients with acute myeloid leukemia. Leukemia 16: 1302-1310.

25. Palgan I, Wysocki M, Palgan K, et al. (2004): Angiogenic cytokines: vascular endothelial growth factor and basic fibroblast growth factor levels in serum of children with hematopoietic malignancies and solid tumors. Blood 11: abstract \#3905.

26. Yang YT, Weng CJ, Ho CT, Yen GC (2009): Resveratrol analog-3,5,49-trimethoxy-trans-stilbene inhibits invasion of human lung adenocarcinoma cells by suppressing the MAPK pathway and decreasing matrix metalloproteinase-2 expression. Mol Nutr Food Res 53: 407-416.

27. Tang Q, Li G, Wei X, et al. (2013): Resveratrol-induced apoptosis is enhanced by inhibition of autophagy inesophageal squamous cell carcinoma. Cancer Lett 336: 325-337.

28. Luo H, Yang A, Schulte BA, et al. (2013): Resveratrol induces premature senescence in lung cancer cells via ROS-mediated DNA damage. PLoS One 8: e60065.

29. Gomez LS, Zancan P, Marcondes MC, et al. (2013): Resveratrol decreases breast cancer cell viability and glucose metabolism by inhibiting 6-phosphofructo-1-kinase. Biochimie 95: 1336-1343.

30. Gokbulut AA, Apohan E, Baran Y (2013): Resveratrol and quercetin-induced apoptosis of human 232B4 chronic lymphocytic leukemia cells by activation of caspase- 3 and cell cycle arrest. Hematology 18: 144-150.

31. Sheth S, Jajoo S, Kaur T, et al. (2012): Resveratrol reduces prostate cancer growth and metastasis by inhibiting the Akt/ MicroRNA-21 pathway. PLoS One 7: e51655.

32. Miki H, Uehara N, Kimura A, et al. (2012): Resveratrol induces apoptosis via ROS-triggered autophagy in human colon cancer cells. Int J Oncol 40: 1020-1028.

33. Fang Y, DeMarco VG, Nicholl MB (2012): Resveratrol enhances radiation sensitivity in prostate cancer by inhibiting cell proliferation and promoting cell senescence and apoptosis. Cancer Sci 103: 1090-1098.

34. Fang Y, Bradley MJ, Cook KM, et al. (2013): A potential role for resveratrol as a radiation sensitizer for melanoma treatment. J Surg Res 183: 645-653.

35. Luo H, Wang L, Schulte BA, et al. (2013): Resveratrol enhances ionizing radiation-induced premature senescence in lung cancer cells. Int J Oncol 43: 1999-2006.

36. Heiduschka G, Lill C, Seemann R, et al. (2014): The effect of resveratrol in combination with irradiation and chemotherapy: study using Merkel cell carcinoma cell lines. Strahlenther Onkol 190: 75-80.

37. Balaiya S, Murthy RK, Chalam KV (2013): Resveratrol inhibits proliferation of hypoxic choroidal vascular endothelial cells. Mol Vis 19: 2385-2392.

38. Alex AF, Spitznas M, Tittel AP, et al. (2010): Inhibitory effect of epigallocatechin gallate (EGCG), resveratrol, and curcumin on proliferation of human retinal pigment epithelial cells in vitro. Curr Eye Res 35: 1021-1033. 